\section{Hipertextos, jogos de computador e comunicaçã̃o}

\section{RESUMO}

Este artigo trata da transformação do computador em um meio de comunicação. Dizer que o computador é um meio de comunicação parece algo óbvio na era da internet. Mas de que meio de comunicação se trata? Para alguns se trata de um multimídia, capaz de integrar os formatos e linguagens de todos os demais meios. Para outros se trata de algo mais do que isso: ao integrar as linguagem dos outros meios, o computador impõe a elas a sua própria lógica. Mas... qual lógica?

\section{ABStract}

\section{palavras-chave}

- Hipertexto

- Cibercultura

- Novas tecnologias

Afonso de Albuquerque Simone Pereira de Sá

Professores da UFF

\section{Infrodução}

CRIADOS NA DÉCADA de quarenta, os computadores passaram por transformações extraordinárias nas duas últimas décadas. Por muito tempo, eles foram identificados como o símbolo maior da sociedade tecnocrática: máquinas gigantescas e desajeitadas, tão eficientes quanto desumanas. Com a revolução dos computadores pessoais na década de oitenta e a explosão da internet na década de noventa, porém, a imagem do computador mudou radicalmente. Equipados com interfaces atraentes e amigáveis, os computadores pessoais se tornaram um objeto do cotidiano, simultaneamente útil, lúdico e educativo. Além disso, eles têm sido freqüentemente representados como tecnologias essencialmente libertárias, na medida em que permitiriam ao usuário interagir com a máquina (e deste modo "humanizá-la"). Do ponto de vista deste artigo, porém, uma mudança importa mais do que todas as outras: a transformação do computador em um meio de comunicação.

Dizer que o computador é um meio de comunicação parece algo óbvio na era da internet. Mas de que meio de comunicação se trata? Para alguns se trata de um multimídia, capaz de integrar os formatos e linguagens de todos os demais meios. Para outros se trata de algo mais do que isso: ao integrar as linguagem dos outros meios, o computador impõe a elas a sua própria lógica. Mas... qual lógica?

Diversos autores têm procurado em conceitos como "hipertexto", "interatividade" e "interface" a solução para o problema. Em linhas gerais, as respostas fornecidas até o presente pecam pela superficialidade. Tal como ocorreu no debate sobre a televisão nas décadas de cinqüenta e sessenta, muita energia tem sido gasta para analisar o potencial de um hipertexto genéri- 
co - se ele liberta o leitor do jugo do autor (é bom) ou produz confusão na leitura (é mau) - mas pouca análise tem sido produzida acerca de exemplos concretos de hipertexto. Embora os hipertextos de tipos mais diversos façam, cada vez mais, parte da nossa vida, o debate acadêmico atual ainda tem pouco a dizer acerca deles, comparativamente ao que ocorre com a literatura e o cinema, por exemplo.

Este artigo considera problemas relativos à lógica do hipertexto tendo como objeto da análise os jogos de computador. Ao contrário do que se verifica com as sofisticadas experimentações da literatura hipertextual ou da "babel criativa" freqüentemente associada à "Grande Rede", os jogos de computador têm sido, de um modo geral, ignorados ou relegados a um segundo plano pelo meio acadêmico. Considerandose o sucesso comercial desses jogos - em 1996, estimava-se que a indústria dos videogames e jogos de computador movimentava no mundo cerca de 15 bilhões de dólares ao ano (Miles, 1999) - é de se admirar que isso ocorra. Ou, talvez, seja exatamente o caráter comercial dos jogos de computador - identificados como mera fruição em oposição à sofisticação intelectual da literatura hipertextual ou, alternativamente, como "pacotes" industrializados em oposição ao campo aberto de possibilidades representado pela internet - que explique tal desdém.

É justamente o caráter impuro, "viralata", dos jogos de computador que faz deles o objeto de interesse deste artigo. Por um lado, está claro que tais jogos proporcionam aos seus usuários um tipo de compromisso muito distinto, no seu percurso do texto, daquele que se verifica na literatura e no cinema tradicionais. Mais do que simplesmente atuar como um intérprete ativo da trama e seu significado, o usuário dos jogos de computador interfere a todo momento nessa trama e no destino dos seus personagens (ele pode causar a morte prematura do protagonista, por exemplo). Em alguma medida, pode-se dizer, portan- to, que o usuário dos jogos desempenha um papel mais "ativo" que o do leitor ou espectador tradicionais.

Por outro lado, é evidente que, também nos jogos de computador, a autonomia do usuário é bastante limitada. Longe de basearem em princípios rizomáticos, como aqueles geralmente associados à lógica do hipertexto, os jogos de computador apresentam tramas consideravelmente fechadas, cujo desenrolar depende de o usuário realizar as operações "corretas", tal como definidas pela lógica do software. Por paradoxal que pareça, faz sentido sugerir que o usuário dos jogos de computador é menos autônomo no seu percurso do texto que o leitor tradicional. A este último é dada a possibilidade de, subvertendo o percurso de leitura proposto pelo autor, ler a qualquer momento as últimas páginas do romance para antecipar o seu final; para o usuário esta possibilidade não se apresenta. Frente a estas características, poder-se-ia simplesmente diagnosticar a inadequação da abordagem, descartando-se estes jogos como experimentos pertinentes à discussão sobre a lógica hipertextual.

Tais observações deixam claro que, quando deixamos de lado o discurso generalista sobre o hipertexto e passamos a considerar objetos concretos e bem delimitados, a questão se revela muito mais complexa do que parecia a princípio. Este artigo pretende apenas expor alguns dos problemas que se apresentam à análise dos jogos de computador como meios de comunicação. Os marcos teóricos dessa discussão são apresentados a seguir: eles dizem respeito, em primeiro lugar à evolução do debate sobre o hipertexto, dentre dos parâmetros do que classificamos aqui como abordagem "generalista"; em seguida consideraremos algumas contribuições à análise dos jogos de computador como meios de comunicação.

\section{Literatura e Hipertexto}

O ponto de partida de nossa discussão 
constitui-se pelo crescente número de trabalhos produzidos em torno do tema "literatura e hipertexto". As obras de Vannevar Bush e Theodore Holm Nelson, pioneiros no estudo do tema, constituem, a este respeito, referências fundamentais.

Credita-se ao artigo "As we may think" de Vannevar Bush, publicado em 1945, a sugestão do conceito de hipertexto. Neste trabalho, o matemático e físico introduz e descreve o Memex - Memory Index chamando a atenção para a necessidade de máquinas de processamento da informação mecanicamente conectadas, que ajudassem estudantes e executivos frente à crescente "enxurrada de informações" e do "problema de seleção" dos métodos tradicionais de recuperação.

Escrevendo antes do advento da utilização do computador em larga escala, Bush concebe o Memex como um dispositivo dotado de grande flexibilidade para se guardar livros, arquivos, documentos de trabalho, traduzido fisicamente numa espécie de mesa com superfícies translúcidas, pranchas e motores para uma busca rápida de arquivos na forma de microfilmes. Dispositivo este capaz de automatizar a recuperação da informação de forma associativa, veloz, flexível e por analogia - "tal como a mente trabalha" - e não por separações artificiais, rígidas e confinadas como as fichas de referência em voga.

O invento mecânico de Bush apresenta dois elementos que serão considerados posteriormente cruciais na concepção do hipertexto. O primeiro é a idéia dos links enquanto sistema de trilhas para a associação flexível de dados. A segunda é a possibilidade de intervenção do leitor, criando seu próprio sistema de anotações e associações. Retomados por Theodor Nelson, Douglas Engelbart, Andries Van Dam e outros criativos pesquisadores dos anos 60, eles dão origem ao conceito de hipertexto enquanto blocos de textos unidos por links e dispostos em forma de rede, já com a ajuda do computador. Segundo Nelson, autor da expressão, o hipertexto representa a "es- crita não seqüencial - texto que ramifica e permite escolhas, melhor lido em uma tela interativa. (...) pedaços de textos conectados por links que oferecem ao leitor diferentes caminhos" (apud Landow; 1992).

Já nos anos 90, quando a reflexão sobre as novas tecnologias consolida-se concomitantemente ao crescente convívio com os computadores interligados em rede, o debate em torno do tema "literatura e hipertexto" também ganha corpo: a obra de Pierre Lévy $(1993 ; 1996 ; 1999)$ e os trabalhos de Landow (1992; 1994) e seus seguidores constituem exemplos bem conhecidos desta tendência.

Pierre Lévy - autor de obra provocadora e bastante divulgada no Brasil - vai entusiasmar-se com as potencialidades desta nova ferramenta tecnológica que pode ser utilizada para a organização de conhecimentos ou dados, a aquisição de informações e a comunicação. Definindo tecnicamente o hipertexto à maneira de Nelson como um conjunto de nós - palavras, imagens, gráficos e seqüências sonoras combinados e disponibilizados como imensa rede acessível em tempo real Lévy ocupa-se principalmente da discussão sobre os princípios de funcionamento do hipertexto. Princípios tais como a metamorfose da rede hipertextual, a heterogeneidade dos nós e das conexões, os princípios de multiplicidade e de encaixe das escalas e de mobilidade de centros - que combinados, garantem a flexibilidade desta nova forma de comunicação reproduzindo a forma como o pensamento pensa pulando de um lado pro outro através de uma rede complexa de associações.

Nesta concepção, o autor enfatiza ainda a importância do conceito de interface na constituição do hipertexto, entendida como a face interativa que permite que se use em toda a extensão o princípio da nãolinearidade, estimulando assim a exploração lúdica e a "atividade" do usuário.

Se a obra de Lévy tem o mérito de provocar a reflexão sobre as potencialidades de diferentes 'tecnologias da inteligên- 
cia", podendo ser pensada no seu conjunto como uma ampla carta de navegação ou uma pauta geral para os principais tópicos da reflexão sobre novas tecnologias e cibercultura, ela deixa também algumas questões irrespondidas sobre a especificidade do hipertexto eletrônico, suas modalidades e usos diversos, sugerindo antes a possibilidade do uso do hipertexto como metáfora.

Neste sentido, as reflexões de George Landow aproximam-se mais estreitamente do objeto de nosso projeto, uma vez que investiga as aproximações entre hipertexto e teoria literária. Enfatizando uma notável convergência entre, de um lado a crítica literária pós-estruturalista e desconstrucionista dos trabalhos de Roland Barthes, que reivindica (em S/Z) o "texto ideal", inacabado e aberto, onde as redes sejam múltiplas e interajam; de Derrida e sua reivindicação da desconstrução textual e avant la lettre, do dialogismo de Bahktin e sua defesa das múltiplas vozes presentes no texto; e por outro, na definição de hipertexto, Landow vai percebê-lo como a possibilidade técnica de corporificação destas idéias onde a crítica às idéias de margem, centro, hierarquia e linearidade é central- substituídas pelas idéias de multilinearide, nós, "links" e rede - advindo daí a importância do hipertexto para a literatura.

Sua argumentacão centra-se, portanto, na oposição entre o texto tradicional instituído pela imprensa, que o autor descreve como, de regra, obra "fechada", delimitada pelas margens, contido pelo índice e pela paginação e assinado pela autoridade detentora da "verdade" textual, que sugere ao leitor como ler e entender a obra, de um lado; e de outro o hipertexto que aponta para reconfigurações nos papéis de autor, do leitor e, conseqüientemente, da própria concepção de texto e de leitura, traduzindo desta forma uma "mudança de paradigma".

No mesmo sentido, alguns de seus colaboradores na obra Hyper/text/theory apostam nas "potencialidades" do hiper- texto, reiterando, de maneira geral, os argumentos de Landow e explorando-os em diversas direções: seja na reconfiguração da política em bases mais democráticas, a partir dos argumentos habermasianos (Ess, 1997); da filosofia em bases mais fluidas, fragmentárias e interrogativas (Kolb, 1997); da narrativa em base não-linear e de integração entre diferentes meios (Liestol, 1997).

Jogos de Computador e Comunicação

O estudo dos jogos de computador como meio de comunicação tem sido objeto de poucos estudos sistemáticos. Dentre eles, podemos destacar as contribuições de Miles (1999), Murray (1997) e Aarseth (1997).

Através da análise do jogo Myst, David Miles se propõe a discutir questões mais gerais acerca das possibilidades expressivas do ambiente multimídia. O referencial teórico da empreitada é constituído pelas quatro Leis dos Media formuladas por McLuhan. De acordo com este autor, meios de comunicação radicalmente novos estabelecem quatro tipos básicos de relacionamento com os meios anteriormente existentes:

1) aceleração;

2) obsolescência;

3) síntese;

4) recuperação.

É este último tipo de relação que constitui o objeto de Miles em sua análise de Myst. Segundo o autor, Myst "representa tanto o início de uma nova forma de arte que sintetiza diferentes meios em novas combinações - e, o que é igualmente importante, recupera e reinventa formas de arte antigas que por muito tempo se supunha obsoletas" (1999: 309).

De acordo com o autor, as referências de Myst incluem obras ou tradições artísticas tão diversas quanto a Odisséia de Homero, o romance gótico, pinturas e filmes surrealistas, além, evidentemente, da ficção interativa derivada de Borges. 
O objeto do interesse de Janet H. Murray é, sob muitos aspectos, semelhante ao de Miles, mas o seu enfoque sobre o problema é muito diferente do deste autor. Diretora do Programa Avançado em Tecnologias de Narrativas Interativas do MIT, Murray acredita que o desenvolvimento das potencialidades expressivas do computador está em sua infância: o computador ainda é visto como um suporte que permite o aperfeiçoamento dos meios de comunicação preexistentes (fotografia digital, por exemplo), antes que como um meio de comunicação de direito próprio. Mal comparando, o computador viveria hoje uma situação semelhante à do cinema primitivo, estruturado em torno do plano único e avaliado a partir do paradigma da fotografia (fotografia em movimento). Assim como aconteceu com o cinema, a evolução do computador como meio de expressão artística dependeria não apenas de inovações técnicas - como as que permitiram o cinema sonoro - mas também de inovações na sua linguagem.

Neste sentido, a caracterização do computador como multimedia seria uma medida de eficácia duvidosa. É bem verdade que o termo aponta corretamente a capacidade do computador de integrar elementos oriundos de meios de comunicação preexistentes; entretanto, ele é incapaz de dar conta do modo particular como essa integração se verifica no computador e os problemas específicos que derivam daí. É preciso, portanto, ir além do paradigma "aditivo" sugerido pelo termo "multimedia" e considerar as possibilidades expressivas específicas do computador.

Murray destaca três elementos fundamentais da lógica do computador como meio de comunicação: a imersão do usuário em cenários criados pelo meio; a agência, ou seja, a capacidade de o usuário intervir na trama ativamente, dentro de parâmetros preestabelecidos; e a transformação, isto é, o estado de constante mutabilidade a que estão sujeitos todos os objetos vivenciados através do computador. $\mathrm{O}$ desafio que se apresenta para o computador como meio de comunicação seria, então, a criação de parâmetros capazes de produzir narrativas interativas, capazes de conciliar a possibilidade de uma ampla intervenção do usuário no universo da trama com a existência de princípios ordenadores, sem os quais nenhuma narrativa é possível. Os jogos de computador têm sido, a este respeito, campos privilegiados de experimentação.

A dupla formação de Murray (profissional experiente no campo da informática e PhD em Literatura), o fato de ela unir à crítica teórica do tema uma experiência prática e a fecundidade de alguns dos seus insights fazem dela uma referência indispensável para o estudo dos jogos de computador. Entretanto, falta à sua obra maiores sistematicidade e rigor conceitual.

$\mathrm{O}$ mesmo não se verifica na obra de Aarseth, que se fundamenta em um sofisticado arcabouço teórico. Tendo por referência a teoria literária, Aarseth estrutura a sua análise em torno dos conceitos de literatura ergódica e cibertexto. O termo ergódico é utilizado para designar um esforço não trivial no percurso de um texto, um esforço que o termo "leitura" não permite caracterizar apropriadamente. A tais textos, que o usuário não apenas lê, mas explora ativamente, simultaneamente como leitor e autor, Aarseth denomina cibertextos. A literatura "ergódica", portanto, busca dar conta dos cibertextos em sua diversidade. $\mathrm{O}$ autor insiste que o cibertexto não compreende uma categoria "nova" ou "revolucionária" de textos que teria surgido a partir das novas tecnologias da informática, mas de uma outra perspectiva acerca da textualidade. Lado a lado com obras de literatura hipertextual de vanguarda como Victory Garden ou jogos como Doom ou Myst, a categoria "cibertexto" comportaria também textos impressos como Paisagem pintada com chá, de Mirolad Pavic, Cent Mille Milliards de Poèmes, de Raymond Queneau e, mesmo, o tradicional I Ching.

Segundo Aarseth, o texto pode ser produtivamente entendido como uma máquina, um dispositivo mecânico para a pro- 
dução e consumo de signos verbais. A literatura tradicional e o cinema pressupõem a adequação tanto do autor quanto do leitor/ espectador a uma ordem - que pode ser, nos textos escritos, da esquerda para a direita ou de cima para baixo e, nos filmes, a seqüência de planos - a uma gramática e uma sintaxe preestabelecidas. Conforme observa Barthes (1973), tais princípios ordenadores permanecem como um referencial mesmo para as obras literárias que se dedicam a subvertê-los. Nos hipertextos eletrônicos, igualmente, a estrutura dos links define as possibilidades e interdições do trajeto efetivado pelo usuário. Ainda que tal estrutura possibilite uma intervenção mais ativa do usuário no texto - ele pode, como resultado da sua escolha, produzir o seu próprio texto - ela é, sob outro aspecto, mais coercitiva: pois, se a estrutura do texto impresso permite ao leitor subverter livremente o trajeto estabelecido pelo autor lendo as últimas páginas de um livro de suspense, por exemplo - nos hipertextos literários e nos jogos de computador esta liberdade é tolhida pela estrutura de links: ainda que o leitor tenha várias opções de leitura, é vedada a ele a possibilidade de seguir um trajeto que não tenha sido previsto no sistema de links.

Para Aarseth, o problema da relação entre autor, leitor e texto apresenta-se, então, como muito mais complexo do que em Landow. Ele não se resume à equação "poder do autor versus liberdade do leitor", mas dá conta de uma certa autonomia do funcionamento do texto tanto em relação ao autor quanto ao leitor (ou usuário). Essa autonomia é particularmente notável nos textos de computador, dada a sua complexidade e a duplicidade fundamental da sua estrutura: tais textos devem se estruturar de modo a que sejam entendidos não apenas pelos seus usuários humanos (como texto), mas também pela máquina (como programa). Um exemplo dessa complexidade é fornecido pelos programas de xadrez que "jogam" melhor do que seus programadores. Outro exemplo do mesmo problema é fornecido pelos bugs dos jogos de computador que, por vezes, estabelecem possibilidades para a trama e efeitos de sentido inesperados.

De acordo com Aarseth, diversos autores têm buscado na teoria do ato de leitura de Iser os subsídios necessários para entender o papel desempenhado pelo usuário dos jogos de computador - particularmente nos jogos do tipo "Adventure". ${ }^{1}$

Segundo Iser (1996), o efeito estético da obra literária se realiza somente no ato de leitura, quando o leitor preenche de sentido os lugares vazios do texto. De maneira homóloga, os autores citados por Aarseth identificam nos jogos do tipo "Adventure" um outro tipo de lugar vazio: uma carência narrativa, que deve ser preenchida pelo usuário para que o texto possa prosseguir.

No entender de Aarseth, porém, tal homologia não se sustenta. Diferentemente do leitor de Iser, que se utiliza da sua intencionalidade para construir sentido acerca do texto, nos jogos de computador o "texto" só pode prosseguir na medida em que o jogador forneça as respostas "apropriadas", segundo a lógica do programa, para os problemas que lhe são propostos. A questão da autonomia do mecanismo dos cibertextos apresenta-se, pois, mais uma vez.

\section{Narrativas interativas?}

A questão das possibilidades oferecidas pelo computador para o desenvolvimento de novos tipos de narrativas, interativas, tem despertado um crescente interesse. Ainda que a atenção do mundo acadêmico tenda a se voltar preferencialmente para as suas aplicações aos campos (mais conceituados) da literatura e do cinema, é no universo dos jogos de computador que o problema tem sido discutido de modo mais consistente.

A expectativa que se tem a este respeito é que as narrativas em meios interativos constituem um caminho para a autono- 
mização do leitor/espectador, uma vez que permitiriam a ele traçar o seu próprio percurso de leitura, de modo consideravelmente autônomo - e, mesmo, potencialmente subversivo - em relação às intenções do autor. Em que medida essa expectativa se sustenta? Tendo por referencial de análise o universo dos jogos de computador, encerramos este artigo com algumas (e inconclusivas) observações a este respeito.

Duas delas dizem respeito à pertinência da terminologia correntemente empregada acerca do problema: em que medida o uso dos termos narrativa e interatividade é adequado para definir com precisão as características de tal tipo de obras de arte? Uma terceira questão refere-se às possibilidades concretas que elas apresentam do ponto de vista de uma tal "leitura subversiva" por parte dos seus usuários.

O estudo da narrativa tem as suas bases solidamente ancoradas no campo acadêmico, a tal ponto uma disciplina - a narratologia - foi especificamente criada para este fim. As origens da narratologia remetem, naturalmente, aos estudos de Propp e dos formalistas russos sobre a morfologia do conto, ainda na década de vinte; e o seu desenvolvimento é em grande parte tributário do estruturalismo francês: LéviStrauss (1985) com sua análise estrutural do mito, Barthes (1976) e Todorov (1970) são algumas das referências centrais neste sentido. Entretanto, é principalmente a Genette (1980) que se atribui a responsabilidade pelo desenvolvimento da narratologia como disciplina sistemática.

De acordo com Genette, o termo "narrativa" tem sido utilizado para dar conta de três dimensões distintas de um mesmo fenômeno: 1) o relato que tem por objeto um evento ou uma série de eventos; 2) os eventos que se fazem objeto desse discurso; 3$)$ o ato de narrar propriamente dito.

A essas três dimensões do fenômeno narrativo ele propõe denominar respectivamente narrativa, história e narração.

A narratologia teria como seu objeto privilegiado o estudo da narrativa (no sen- tido específico do termo) e suas relações com a história e a narração.

No início, a narratologia encontrou na literatura o seu objeto privilegiado: Narrative Discourse, de Genette é, simultaneamente uma exposição do método narratológico e uma análise da narrativa da obra $A$ la recherche du temps perdu, de Proust. Prontamente, porém, a aplicação da narratologia se estendeu a outros campos de investigação, como por exemplo o cinema. Compartilhando da mesma base teórica da sua "parente" literária, a narratologia cinematográfica - desenvolvida por autores como Chatman (1981), Bordwell (1985) e Gaurdreault e Jost (1995) - tem se esforçado por investigar os problemas específicos que o filme apresenta à teoria narrativa. Problemas que dizem respeito, por exemplo, à instância narrativa do cinema (quem narra?) ou às diferenças entre descrever (literatura) e mostrar (cinema), e os problemas específicos que isso apresenta do ponto de vista da narrativa.

Se a teoria narrativa pode ser adaptada do estudo da literatura para o do cinema, por que então ela não poderia também ser aplicada ao estudo da literatura hipertextual? Dentre os diversos autores que têm explorado esta questão, talvez seja Liestol que o tenha feito de modo mais sistemático. De acordo com ele, o hipertexto e os hipermeios acrescentam um terceiro nível à dicotomia (que ele associa a Genette) entre história e discurso: o nível do discurso discorrido, que se estrutura a partir da seleção e combinação de elementos já existentes e estruturados em links no texto armazenado em forma digital. No romance hipertextual, portanto, os princípios-chave da estruturação narrativa e, portanto, as operações básicas da autoria são transferidas do autor ao leitor, do escritor primário ao escritor secundário.

O argumento de Liestol apresenta várias inconsistências, das quais a mais evidente e importante diz respeito à redução dos três níveis da narrativa de que trata Genette a apenas dois, deixando de lado o âm- 
bito da narração. Deste modo, a análise de Liestol deixa de lado uma série de importantes questões que têm sido tradicionalmente investigadas pela narratologia, tais como os problemas da focalização e o problema da instância narrativa. E o que ele apresenta em contraposição? Efetivamente, muito pouco. Embora seja correto dizer que o leitor participa ativamente da construção de uma narrativa (no sentido de história) particular, é pouco apropriado caracterizar como narração a atividade de executar comandos cujas conseqüências o usuário do texto não conhece, bem como caracterizar como discurso o produto dessa atividade.

O conceito de interatividade, por sua vez, assenta-se sobre bases muito menos sólidas. Tanto Jensen (1999) como Aarseth (1997) concordam que as definições de interatividade correntemente empregadas são pouco rigorosas e refletem a importação acrítica de conceitos da indústria da informática pela comunidade acadêmica. Embora compartilhem de um mesmo diagnóstico sobre o problema, o caminho trilhado por ambos com relação ao problema é bastante distinto.

No seu esforço para definir o termo "interatividade" com precisão, Jensen julga conveniente distingui-lo de um outro termo, "interação", com o qual ele guarda evidentes relações. $\mathrm{O}$ autor propõe usar o termo "interação" para caracterizar "a relação entre duas ou mais pessoas que, em uma dada situação, adaptam seu comportamento e suas ações em referência aos outros" (Jensen, 1999: 165). O termo "interativida$\mathrm{de}^{\prime \prime}$, por sua vez, é reservado para o uso dos media ou à comunicação que se estabelece através deles. Neste sentido, a interatividade poderia ser definida como "a medida da capacidade potencial de um meio de comunicação de deixar que o usuário exerça influência sobre o controle ou forma da comunicação mediada" (183). Baseado no modelo de tipologia dos meios de comunicação de Bordewijk e Kaam, Jensen distingue quatro dimensões diferentes nas quais se exerce a interatividade:

1) Interatividade transmissional: a capacidade de um meio de permitir ao usuário escolher, dentre o conjunto de informações transmitidas por um meio de via única sem a possibilidade de retorno - aquelas do seu interesse (um exemplo singelo é o de um sistema de televisão com múltiplos canais).

2) Interatividade consultacional: a capacidade de um meio de permitir ao usuário escolher as informações que lhe interessam acessando, através de um sistema de comunicação de via dupla, o conjunto das informações disponíveis (é o caso do FTP, WWW, Enciclopédias em CD-ROM, etc.).

3) Interatividade conversacional: a capacidade de um meio de permitir ao usuário introduzir as suas próprias informações em um sistema de comunicação de via dupla (é o caso do e-mail, das listas de discussão).

4) Interatividade registracional: a capacidade de um meio de registrar, se adaptar e, de algum modo, responder a informações produzidas pelo usuário, com ou sem o seu consentimento expresso (os jogos de computador fornecem um exemplo do primeiro caso e os cookies, que rastreiam o trajeto de um usuário através da internet fornecem um exemplo do segundo).

As distinções entre os conceitos de "interação" e "interatividade" e entre diferentes tipos de interatividade afastam Jensen do argumento que identifica qualidades libertadoras nas novas tecnologias "interativas" de comunicação, ainda que não o ponham em confronto direto com ele.

Isso se dá porque, no final das contas, Jensen evita discutir em profundidade o problema das relações concretas que os usuários estabelecem com essas tecnologias, centrando o seu foco nas potencialidades que elas apresentam a este respeito.

Aarseth volta a sua atenção mais espe- 
cificamente para o problema da ficção interativa. Tal como Jensen, Aarseth identifica, no modo como o termo "interatividade" tem sido utilizado para descrever as modernas tecnologias da comunicação, uma tendência à fetichização. Sugere-se "que humanos e máquinas são parceiros equivalentes, simplesmente por conta da capacidade da máquina de aceitar e responder ao input humano" (1997: 48).

A mesma imprecisão conceitual se estende, segundo ele, ao termo "ficção interativa". Dado que toda obra ficcional depende de um engajamento ativo do usuário de modo a lhe emprestar sentido (Iser), o uso da expressão "interativo" para qualificar um determinado tipo de ficção parece excessivo e reduntante.

Por outro lado, Aarseth argumenta que, nos jogos de computador do tipo "Adventure", o usuário não pode se fiar apenas em sua imaginação e experiência prévia, mas tem que lidar com as leis de natureza não-ficcional (a lógica do programa) para dar andamento à trama. Daí por que ele prefere utilizar o termo "ergódica" antes que "interativa" para caracterizar este tipo de ficção.

Isso nos conduz à nossa última questão: em que medida os hipertextos ou cibertextos ampliam ou não as possibilidades de uma interpretação "subversiva" pelo usuário? A idéia de que a audiência desempenha um papel ativo na interpretação do sentido das mensagens a ela dirigidas tem sido moeda corrente no estudo dos meios de comunicação de massa desde a década de setenta.

$\mathrm{O}$ artigo "Encoding/Decoding", de Stuart Hall, originalmente publicado em 1973, é geralmente reconhecido como o marco fundador do debate. Nele, Hall apontava a necessidade de se ultrapassar o modelo linear da comunicação - emissor / mensagem/receptor - e sugeria a pertinência de se considerar a comunicação como um circuito contínuo de comunicação do qual a "codificação" e a "decodificação" constituem dois momentos. Em particular,
Hall aplica o seu modelo à televisão e sugere que a análise desse processo deve necessariamente levar em conta as estruturas de significação em ação tanto no momento da codificação quanto no da decodificação das mensagens. Não é este o lugar para discutir em profundidade o argumento de Hall.

É suficiente notar que ele identifica três possibilidades fundamentais no processo da comunicação: a posição dominante/ hegemônica, na qual o espectador introjeta o código dominante ; a posição do código negociado, na qual opera com algumas exceções e ressalvas o código dominante; e a posição oposicional, no qual o espectador decodifica a mensagem em um sentido globalmente contrário ao pretendido ao dominante.

Ainda que a análise de Hall não tenha dispensado muita atenção à análise das possibilidades de uma tal interpretação oposicional, diversos autores fizeram dela o seu objeto de estudo privilegiado (Fiske, 1991; Steiner, 1991).

Não é de espantar que o advento das tecnologias da comunicação ditas "interativas" - particularmente aquelas estruturadas em torno do computador - tenha despertado tanta esperança entre os defensores da "audiência ativa". Se, raciocinam eles, a possibilidade de uma audiência ativa e subversiva se apresenta mesmo em meios caracteristicamente unidirecionais como a televisão, ela seria naturalmente muito maior em meios bidirecionais, ou interativos.

À primeira vista, tal raciocínio faz todo sentido. Entretanto, quando analisado em profundidade o problema se revela muito mais complexo do que parecia a princípio. Afinal, como algumas análises sugerem, a autonomia do usuário em relação ao texto não somente não é necessariamente maior nos hipertextos e cibertextos que nos textos "clássicos", como pode mesmo ser, em muitos casos, menor, uma vez que a atividade do usuário é, neles, fortemente condicionada pelas exigências do 
programa do computador. Os dilemas que isto apresenta são particularmente evidentes nos jogos de computador, dado que, neles, o grau de consentimento que é exigido do usuário em relação à trama é muito maior que o que se requer do leitor de um livro ou do espectador de um filme: ainda que estes últimos desempenhem um papel ativo na trama, é na condição de intérpretes/testemunhas que eles o fazem; nos jogos de computador, por sua vez, o que se exige do usuário é uma cumplicidade ativa com a trama e seu(s) protagonista(s).

Um espectador pode, hipoteticamente, se identificar com os vietnamitas enquanto assiste ao filme Rambo II, por exemplo. Decerto, ele terá inúmeras razões para se frustrar, mas ainda assim poderá chegar ao fim da trama.

Por sua vez, em um jogo como Doom, o jogador não tem alternativa a não ser participar da orgia de sangue alienígena que lhe é proposta (ou convencer a um espírito menos pacifista que ele a fazê-lo) se quiser conhecer o final da história.

Decerto, os jogos de computador apresentam para o seu usuário a oportunidade de participar da trama de modo muito mais ativo que os livros ou filmes. Entretanto, como já foi observado em relação às cartas-corrente políticas (Sá \& Albuquerque, 2000, no prelo), maior atividade não implica, necessariamente, maior autonomia; ela pode mesmo implicar o seu oposto: um maior comprometimento com a trama e, de algum modo, com a ideologia que lhe é implícita. Tal contradição constitui uma questão crucial a ser enfrentada no estudo do computador como meio de comunicaçå

\section{Nota}

1 Pioneiro entre os jogos de computador, Adventure adapta a trama do conhecido RPG (Role Playing Game) Dungeons and Dragons para o computador. Criado na década de setenta, o jogo não contava com qualquer outro recurso além do texto escrito. Usando comandos verbais simples como "go north" ou "hit troll", o jogador tenta agir e se movimentar em um espaço que não pode "ver", mas apenas imaginar com a ajuda das informações prestadas pela "voz" do programa, que presta informações dos lugares onde 0 jogador ingressa e sobre as consequêencias das suas ações. Com o aumento da capacidade de processamento e memória dos computadores, 0 desenvolvimento das interfaces gráficas e de novos suportes como o CD-ROM, o gênero migrou de um ambiente puramente textual para outro, de imagens e sons, primeiramente bidimensional e, depois, tridimensional.

\section{Referências}

AARSETH, Espen J. "No linealidad y teoría literaria". In LANDOW, Georges. Teoría del Hipertexto. Barcelona: Paidós, 1997, pp. 71-106.

AARSETH, Espen J. Cybertext: Perspectives on Ergodic Literature. The Johns Hopkins University Press, 1997.

BARTHES, R. O prazer do texto. São Paulo: Perspectiva, 1973.

BAL, Mieke. Introduction to the Theory of Narrative. Toronto: University of Toronto Press, 1985.

BARTHES, Roland. "Introdução à análise estrutural da narrativa". In BARTHES, Roland et alii, Análise estrutural da narrativa. Petrópolis: Vozes, 1976, 4a ed., pp. 19-60.

BARTHES, Roland. S/Z.Paris, Ed du Seuil, 1970.

BORDWELL, David. Narration in the Fiction Film. Madison: The University of Wisconsin Press, 1985.

BUSH, Vanevar. "As we may think". In MAYER, Paul (org.) Computer Media and Communication: a Reader. Oxford (NY). Oxford University Press, 1999.

CHATMAN, Seymour. "What Novels Can Do That Films Can't (and Vice Versa)". In MTCHELL, W. J. T. (ed.). On Narrative. Chicago: The University of Chicago Press, 1981.

ESS, Charles. "El ordenador político. Hipertexto, democracia y Habermas". In LANDOW, Georges. Teoría del Hipertexto. Barcelona: Paidós, 1997, pp. 259-303.

FISKE, John. "Television: Polysemy and Popularity". In 
AVERY, Robert K. \& EASON, David. Critical perspectives on media and society. New York, London: The Guilford Press, 1991, pp. 346-364.

GAUDREAULT, André \& JOST, François. El relato cinematográfico. Barcelona: Paidós, 1995.

GENETTE, Gérard. "Fronteiras da narrativa". In BARTHES, Roland et alii, Análise estrutural da narrativa. Petrópolis: Vozes, 1976, 4a. ed., pp. 255-274.

GENETTE, Gérard. Narrative Discourse: an Essay on Method. Ithaca (NY) Cornell, 1980.

HALL, Stuart. "Encoding/decoding" In HALL, Stuart \& alii. Culture, media, language. London: Hutchinson/CCCS, 1980.

ISER, Wolfgang. 0 ato da leitura: uma teoria do efeito estético. São Paulo: Editora 34, 1996, 2 volumes.

JENSEN, Jens. "Interactivity: Tracking a New Concept in Media and Communication Studies". In MAYER, Paul (org.) Computer Media and Communication: a Reader. Oxford (NY). Oxford University Press, 1999, pp. 160-187.

JOYCE, Michael. "Sustituyendo ao autor: Un libro en ruinas". In NUNBERG, Geoffrey (comp.) El futuro del libro. Barcelona, Paidós, 1998. pp.279-302.

KOLB. David. "Socrates en el labirinto". In LANDOW, Georges. Teoría del Hipertexto. Barcelona: Paidós, 1997, pp. 259-303.

LANDOW, George. Hypertext. The Convergence of Contemporary Critical Theory and Technology., The John Hopkins University Press., 1992.

LANDOW, George (comp.). Hypertext Theory. The John Hopkins University Press., 1994.

LÉVI-STRAUSS, Claude. "A Estrutura dos Mitos". In Antropologia Estrutural. Rio de Janeiro: Tempo Brasileiro, 1985, 2a ed.

LÉVY, Pierre. As tecnologias da inteligência: o futuro do pensamento na era da informática. São Paulo: Ed 34, 1993.

LÉVY, Pierre. O que é o virtual? São Paulo: Ed 34, 1996.

LÉVY, Pierre. Cibercultura. São Paulo: Ed 34, 1999.
LIESTOL, Gunnar. "Wittgenstein, Gennette y la narrativa del lector en hipertexto". In LANDOW, Georges. Teoría del Hipertexto. Barcelona: Paidós, 1997, pp. 107-145.

MILES, David. "The CD-ROM Novel Myst and McLuhan's Fourth Law of Media: Myst and its "Retrievals". In MAYER, Paul (org.) Computer Media and Communication: a Reader. Oxford (NY). Oxford University Press, 1999, pp. 307-319.

MURRAY, Janet H. Hamlet on the Holodeck: the Future of the Narrative in Cyberspace. Cambridge (Mass.): The MIT Press, 1997.

NELSON, Theodore. Literary Machines, Swarthmore, Pa. Publ. do autor, 1981.

SÁ, Simone Pereira de, e ALBUQUERQuE, Afonso de. "A tragédia dos ursos e outras mensagens: observações sobre a e-política e a globalização". Texto apresentado no IX Encontro Anual da COMPÓS. Porto Alegre, 2000.

STEINER, Linda. "Oppositional Decoding as an Act of Resistance". In AVERY, Robert K. \& EASON, David. Critical Perspectives on Media and Society. New York, London: The Guilford Press, 1991, pp. 329-348.

TODOROV, Tzetan. As estruturas narrativas. São Paulo: Perspectiva, 1970. 